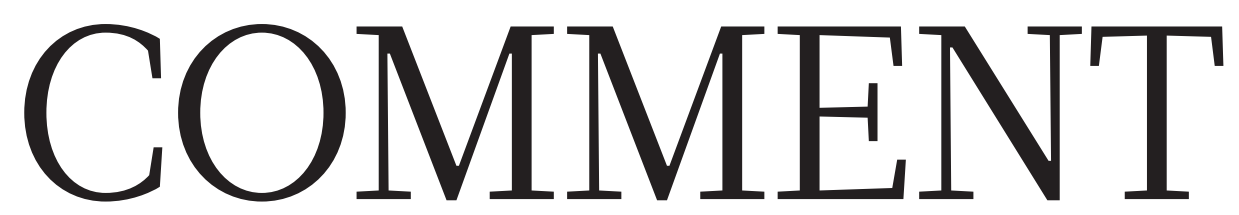

NEUROSCIENCE Researchers and designers should make brain games $\mathbf{p . 4 2 5}$

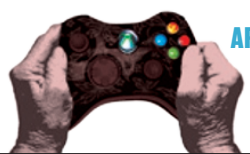

ARCHITECTURE Ersatz new cities overlook local genius p.427
THEATRE Does a lean new version of Brecht's idealistic Life of Galileo work? p.428
CREATIVITY Opportunities for scientific genius are nowhere near exhausted $\mathbf{p . 4 3 0}$

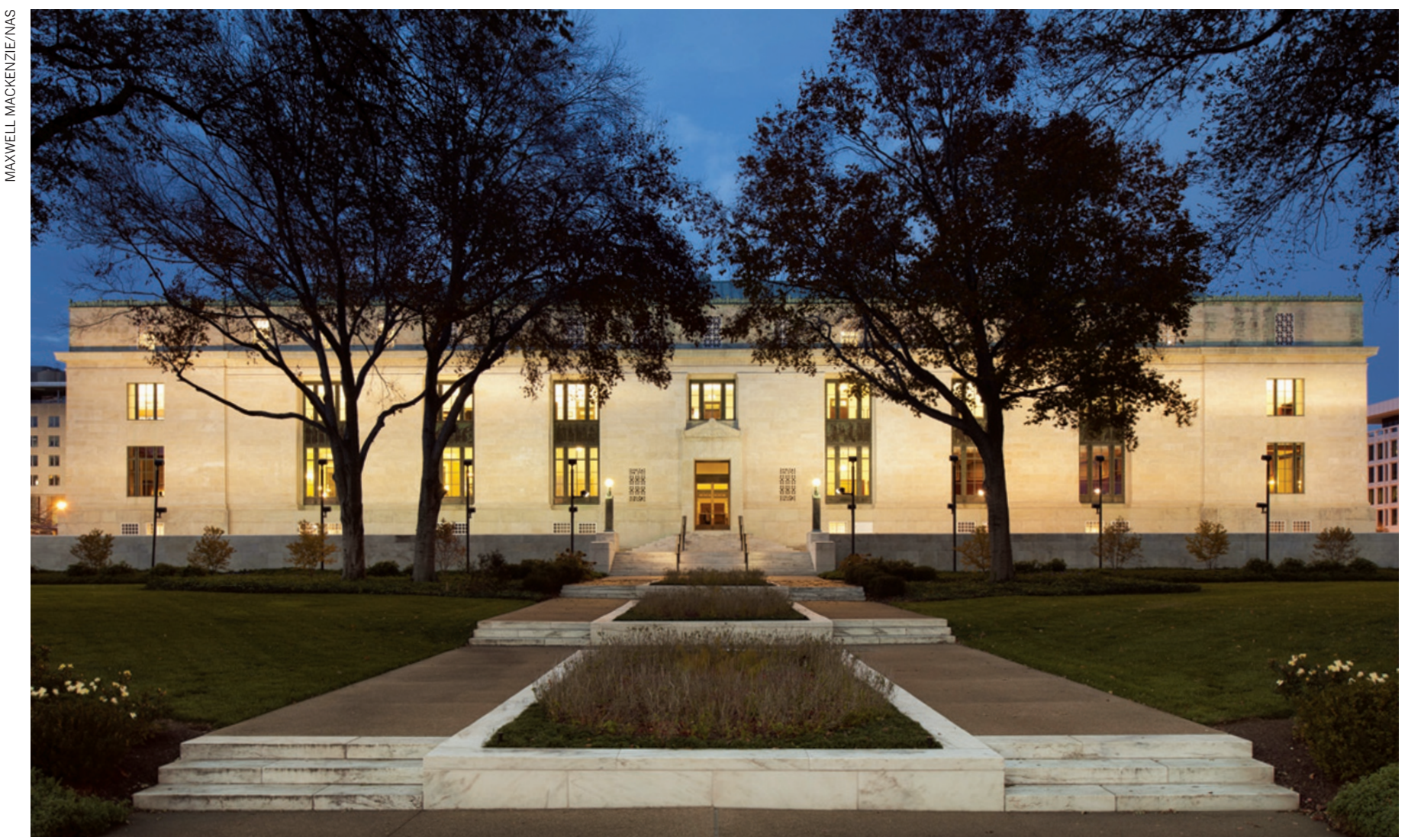

The US National Academy of Sciences has a long history of advising the nation on a range of scientific issues.

\title{
Move with the times
}

\section{The US National Academy of Sciences has to become more nimble and responsive if it is to survive another 150 years, says Marjory S. Blumenthal.}

$\mathrm{I}$ n 1987, I became the executive director of the Computer Science and Technology Board at the US National Academy of Sciences (NAS) in Washington DC, charged with building and managing the new unit. I was to work to: develop and assure the quality of reports, which compile expert advice by the board on various issues in information technology (IT); build a portfolio of projects; and, in time, hire staff to work with committees under the board's aegis.

During my first weeks on the job, reality set in. I was told that three previous boards dedicated solely to IT issues had been shut down. One had run out of funding, one had run out of ideas for new reports and the other had run out of both. Three years later, a telecommunications board with roots in the 1960s failed to secure funding from the US government and was absorbed by my group, which since then has been known as the Computer Science and Telecommunications Board.

These cautionary tales haunted me throughout my 16-year tenure at the NAS. And the day-to-day realities of developing, conducting and overseeing 'academy studies' has taught me that support for the academy is not guaranteed, and that if its components don't stay useful and competitive, they are unlikely to survive.

This concern has never been more acute. The NAS, the first independent body to provide the US government with advice on science (natural and social), engineering and medicine, turns 150 on 3 March. In 2011, it received more than US\$320 million from private donors and federal funding, the latter being its main source of revenue. But 
today, information, even from experts, is much more available and spans a greater range of topics. Venerability is not as compelling as it once was. As politics become more contentious, policy-makers are seeking faster advice, and organizations that offer advice are proliferating.

Twenty-first-century realities demand that the NAS provide expert advice more quickly and do better at explaining its value. If not, then much of the organization could go the way of those ill-fated computer and telecommunications boards.

\section{ADDED VALUE}

The premium NAS product is the committee-study report. It is valuable because of the balance of expertise that goes into its drafting and rigorous review. The beauty of the academy is that it brings together experts with varied backgrounds and opinions to create an unbiased set of recommendations.

But reports often take at least 2 years to produce - and thus many are faulted for being slow or late. There are numerous reasons why they take so long; most stem from the standard process to develop them.

Typically, a government organization asks for input on an issue (sometimes one suggested by an NAS board) - for instance, what is cybersecurity, why is enhancing it hard and what can be done to improve it. NAS staff then develop a project proposal and associated budget, and compile a slate of volunteer experts (usually from academia and industry) who provide a range of perspectives and opinions on the problem. After meetings and discussions, the committee is expected to come to a consensus. Projects have tentative deadlines, and how well they are met depends on the interactions among committee members, the committee chair and the staff.

The process involves multiple layers of expert review and approval: of project proposals (including budgets), committee nominations and draft reports. Plus, there are many layers of internal review - for instance, boards are overseen by divisions, the next tier in the hierarchy. This is great for quality assurance - all of the 60 or so reports in which I was involved benefited from the review - but it is time-consuming. There are a great number of steps and each one depends on external, volunteer experts who typically have busy lives and fit in their committee (or board or division or reportreview) service as an 'extra-curricular' activity. The odds of every participant doing his or her job on time are low. Furthermore, coming to consensus takes time.

For example, the project that produced Signposts in Cyberspace (2005), a report about how to assign domain names to new websites, was a perfect storm of challenges. The project was slow to launch owing to delays in government funding and difficulties in finding neutral experts. Designating a website .com, .org or any of a number of terms might seem like a simple task, but these labels serve a gating function for how individuals or entities represent themselves online. The associated cauldron of technical, commercial, political and advocacy issues, which continues to boil, made composing a committee and finding a neutral chair particularly hard.

The report - which recommended ways to add to the stock of 'top-level domains' such as .com, and other improvements - took 7 years to produce after the congressional request. Although the committee's emphases and arguments evolved over time to maintain relevance, those who disagreed with the report invoked lateness as a criticism.

\section{FIVE CHANGES}

The NAS could overcome this internal bureaucracy and hold its own against external competition by making five changes:

Streamline its structure. The organization should eliminate unnecessary internal review. For instance, some boards can manage their own project development, so do not require oversight from divisions.

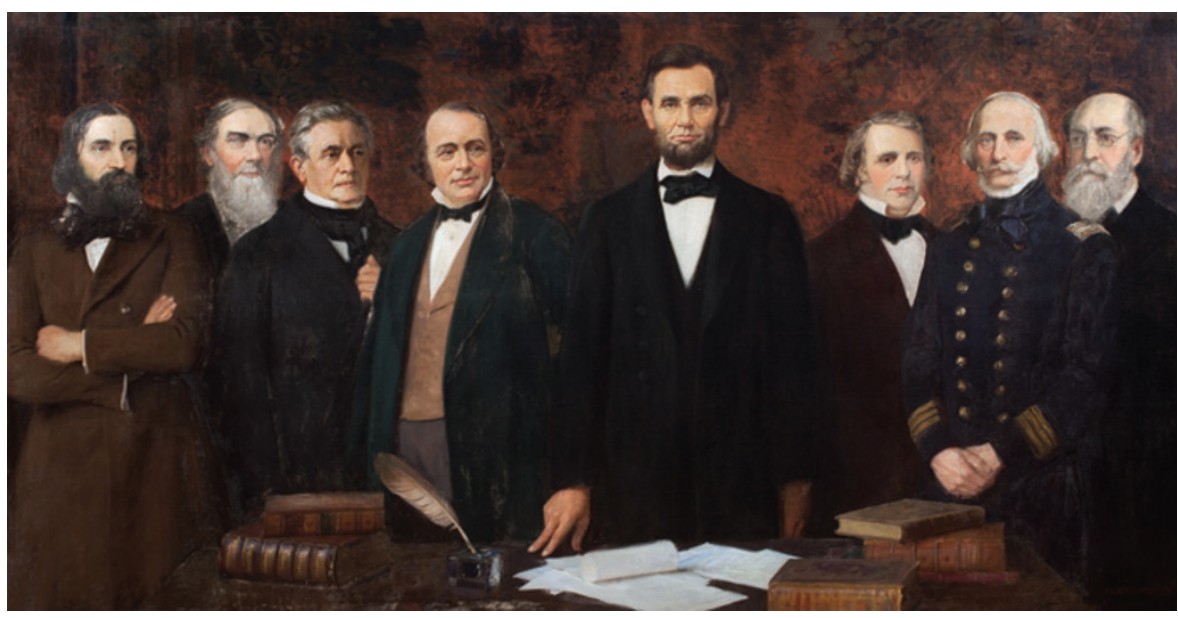

President Abraham Lincoln at the signing of the academy's charter in 1863.

Empower staff. They can help to complete reports quickly. This may involve negotiating more effectively with experts who are not meeting their deadlines, or even contributing more to the writing. The key is to lessen the time that staff spend waiting passively for volunteer input. In some parts of the academy, such as the

"Twenty-firstcentury realities demand that the NAS provide expert advice more quickly and do better at explaining its value."

\section{Institute of Medi-} cine, that approach already works well.

Make meetings more effective. Projects may meet as frequently as every four weeks. Cutting back on meetings is very hard to do well, because the purpose of the NAS is to bring together experts with different points of view, making consensus difficult and time-consuming. But on some projects, I was able to forge a consensus with one big meeting and a series of smaller ones, which probably saved at least 6 months.

Experiment with technology. Committee members and staff could, for example, use blogs, wikis and other social media to share and respond to what is being generated. The NAS could even make some tools public so that people beyond the board can provide input, along with a system that enables the academy to distil out high-value comments with ease. Technology may also help to bring in more international experts, transcending the challenge of funding and organizing face-to-face meetings. This would render the advice of the organization more pertinent for a global audience.

Act as a clearing house. The tradition of layering expertise and balancing biases suggests that the NAS could be an ideal host for structuring, motivating (including by finding ways to give credit) and vetting science and engineering opinions that could come from either known expert communities or from a more varied and diffuse set of participants.

Although there is now more competition than there was 150 years ago, other organizations that offer expert advice tend to be staffed by advocates who are trying to advance a particular point of view. The NAS must become more vocal in explaining why its processes work, and it should experiment with alternative ways to produce highquality, authoritative and unbiased analysis. A major anniversary is a great occasion for an innovation initiative of its own.

Marjory S. Blumenthal is associate provost at Georgetown University in Washington DC. e-mail:blumentm@georgetown.edu 